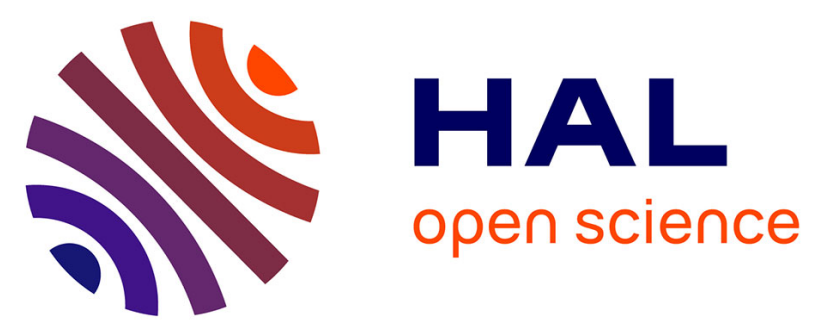

\title{
Differential expression of id genes and their potential regulator znf238 in zebrafish adult neural progenitor cells and neurons suggests distinct functions in adult neurogenesis
}

\author{
Nicolas Diotel, Tanja Beil, Uwe Strähle, Sepand Rastegar
}

\section{To cite this version:}

Nicolas Diotel, Tanja Beil, Uwe Strähle, Sepand Rastegar. Differential expression of id genes and their potential regulator znf238 in zebrafish adult neural progenitor cells and neurons suggests distinct functions in adult neurogenesis. Gene Expression Patterns, 2015, 19 (1-2), pp.1-13. 10.1016/j.gep.2015.05.004 . hal-01692747

\section{HAL Id: hal-01692747 \\ https://hal.univ-reunion.fr/hal-01692747}

Submitted on 6 Feb 2018

HAL is a multi-disciplinary open access archive for the deposit and dissemination of scientific research documents, whether they are published or not. The documents may come from teaching and research institutions in France or abroad, or from public or private research centers.
L'archive ouverte pluridisciplinaire HAL, est destinée au dépôt et à la diffusion de documents scientifiques de niveau recherche, publiés ou non, émanant des établissements d'enseignement et de recherche français ou étrangers, des laboratoires publics ou privés. 


\title{
Differential expression of $i d$ genes and their potential regulator znf238 in zebrafish adult neural progenitor cells and neurons suggests distinct functions in adult neurogenesis
}

\author{
Nicolas Diotel a, b, c, *, Tanja Beil a , Uwe Strähle ${ }^{\text {a }}$, Sepand Rastegar ${ }^{\text {a, * }}$ \\ ${ }^{a}$ Karlsruhe Institute of Technology, Campus Nord, Institute of Toxicology and Genetics, Karlsruhe, Germany \\ ' Inserm, UMR 1188 Diabète athérothrombose Thérapies Réunion Océan Indien (DéTROI), Plateforme CYROI, Sainte-Clotilde, F-97490, France

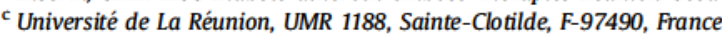

\section{A B S T R A C T}

Teleost fish display a remarkable ability to generate new neurons and to repair brain lesions during adulthood. They are, therefore, a very popular model to investigate the molecular mechanisms of constitutive and induced neurogenesis in adult vertebrates. In this study, we investigated the expression patterns of inhibitor of DNA binding (id) genes and of their potential transcriptional repressor, znf238, in the whole brain of adult zebrafish. We show that while id1 is exclusively expressed in ventricular cells in the whole brain, id2a, id3 and id4 genes are expressed in broader areas. Interestingly, znf238 was also detected in these regions, its expression overlapping with id2a, id 3 and id4 expression. Further detailed characterization of the id-expressing cells demonstrated that (a) id1 is expressed in type 1 and type 2 neural progenitors as previously published, (b) id2a in type 1, 2 and 3 neural progenitors, (c) id 3 in type 3 neural progenitors and (d) id4 in postmitotic neurons. Our data provide a detailed map of id and $z n f 238$ expression in the brain of adult zebrafish, supplying a framework for studies of $i d$ genes function during adult neurogenesis and brain regeneration in the zebrafish.

\section{Introduction}

Adult neurogenesis is a conserved feature of the central nervous system across vertebrates. In mammals, the capacity to generate new neurons during adulthood is limited to two main regions of the telencephalon: the subventricular zone (SVZ) of the lateral ventricle and the subgranular zone (SGZ) of the dentate gyrus in the hippocampus (Braun and Jessberger, 2014; Grandel and Brand, 2013). In contrast, adult zebrafish exhibit widespread neurogenesis throughout the whole brain during their entire lifespan (Edelmann et al., 2013) and possess a high regenerative capacity for repairing lesions of the central nervous system (Diotel et al., 2013; Grandel and Brand, 2013; Lindsey and Tropepe, 2006;

\footnotetext{
* Corresponding authors. Karlsruhe Institute of Technology, Campus Nord, Institute of Toxicology and Genetics, Karlsruhe, Germany.

E-mail addresses: nicolas.diotel@univ-reunion.fr (N. Diotel), Sepand.Rastegar@ kit.edu (S. Rastegar).
}

März et al., 2011; Zupanc, 2008; Zupanc et al., 2005). This strong neurogenic activity is enabled by the persistence of neural progenitors during adulthood (Adolf et al., 2006; Lindsey et al., 2012; März et al., 2010; Pellegrini et al., 2007; Schmidt et al., 2013). The ventricular telencephalic neural progenitors of the adult zebrafish can be classified into three distinct types regarding their morphology, division rate and marker expression (März et al., 2010). Type 1 progenitors correspond to quiescent radial glial cells that display a long radial process and express a wide variety of radial glial markers such as the calcium binding protein $S 100 \beta$, the steroid metabolizing enzyme aromatase $\mathrm{B}$, the brain lipid binding protein (blbp) or the glial fibrillary acidic protein (gfap). Type 2 progenitors are actively dividing radial glial cells, and are consequently expressing proliferating cell nuclear antigen (PCNA) in addition to the markers found in quiescent stem cells. Finally, type 3 progenitors are fast dividing cells with absent or very low expression of radial glial cell markers, but which express the polysialylated neuronal cell adhesion molecule (PSA-NCAM). Type 3 
cells have been proposed to correspond to neuroblasts, the more committed precursors of differentiating neurons (März et al., 2010; Schmidt et al., 2013).

Although the neurogenic capacities of teleost fish are well documented, only a limited number of studies have investigated the expression and potential involvement of regulatory factors known to play key roles in mammalian neurogenesis. Among these factors, helix-loop-helix (HLH) and basic helix-loop-helix (bHLH) proteins are important regulators of transcription that play crucial roles in cell proliferation, differentiation and survival during early development and adult life (Lasorella et al., 2014; Norton, 2000; Patel et al., 2015). Their HLH regions mediate homo or heterodimerization, a step necessary for DNA binding through the basic domain. Inhibitors of DNA binding (Id) proteins belong to the HLH family and lack the basic DNA binding domain. They act as dominant negative regulators by binding to the HLH domains of bHLH factors, thereby preventing their binding to DNA (Lasorella et al., 2014; Ling et al., 2014; Norton, 2000; Perk et al., 2005). In mammals, four different Id proteins encoded by distinct genes (Id1-Id4) have been described (Norton, 2000). They are involved in multiple physiological and pathological processes, acting on cell growth, differentiation, senescence and survival (Lasorella et al., 2014; Ling et al., 2014; Sikder et al., 2003; Yokota, 2001). The different Id genes play key roles in embryonic and adult neurogenesis by regulating quiescence and self-renewal of neural stem cells as well as neuronal differentiation (Aloia et al., 2015; Bai et al., 2007; Havrda et al., 2008; Jen et al., 1997; Jung et al., 2010; Lyden et al., 1999; Nam and Benezra, 2009; Neuman et al., 1993; Ohtaka-Maruyama et al., 2007). Given that expression patterns of Id proteins strongly overlap in various tissues, redundancy in their function has been suggested (Langlands et al., 1997; Sun et al., 1991). Indeed, Id1 and Id 3 functions in the mouse brain are partially redundant, as a single knock-out for either Id 1 or Id3 has almost no effects on brain development, whereas double knock-out mice exhibit precocious neurogenesis (Bai et al., 2007).

Recently, the $\mathrm{C}_{2} \mathrm{H}_{2}$-type zinc finger protein $\mathrm{Rp} 58$, the product of the $\mathrm{Znf} 238$ gene, has been shown to negatively regulate Id genes in the developing cerebral cortex of mouse. Rp58 contributes to the regulation of both neuronal and astroglial differentiation (Hirai et al., 2012). In addition, it modulates proliferation of neural progenitors, neuronal migration and neuronal differentiation during cortical development (Baubet et al., 2012; Hirai et al., 2012; OhtakaMaruyama et al., 2007; Xiang et al., 2012). It is currently not understood whether these effects are all mediated via Rp58 regulation of Id expression, or whether Rp58 also regulates other genes functioning in this context. Consistent with the latter hypothesis, Rp58 negatively regulates Rnd2 (a RhoA-like GTPase), which plays an important role in the control of neural migration during cerebral corticogenesis in mouse (Heng et al., 2015).

In zebrafish, five id genes have been identified (id1, id2a, id2b, id3 and id4; www.ensembl.org) and were shown to have distinct but partially overlapping expression patterns during embryogenesis (Armant et al., 2013; Chong et al., 2005; Dickmeis et al., 2002; Sawai and Campos-Ortega, 1997; Thisse et al., 2001). In the adult zebrafish telencephalon, id1 was recently shown to control homeostatic and regenerative neurogenesis by promoting stem cell quiescence (Rodriguez Viales et al., 2015). Expression and function of the other four id genes in the zebrafish central nervous system during adulthood are only poorly documented, which raises the question whether they also contribute to the regulation of adult neurogenesis. Notably, some aspects of Id 1 function may have been masked by potential redundancy with these other Id members. Additionally, the zebrafish genome also contains one homologue of $z n f 238$, the expression and function of which has not yet been studied.
Given the redundancies of Id genes function in other model organisms (Bai et al., 2007), we decided to investigate their expression in the whole zebrafish adult brain by in situ hybridization. Together with the expression of their potential negative regulator Rp58 encoded by the znf 238 gene, we thereby aimed to create a map of potential Id activity. We placed particular emphasis on the expression patterns in the different telencephalic progenitor cell types. With this, we provide a framework for studies of $i d$ genes function during adult neurogenesis and brain regeneration in the zebrafish.

\section{Results}

\subsection{Id and znf238 genes expression in the brain of adult zebrafish}

In mammals, id genes and their negative regulator znf 238 are expressed in neurogenic niches. To examine if the zebrafish homologues of these genes are expressed in similar regions and also show enriched expression in the additional neurogenic areas of the teleost brain, we first mapped expression of id1-4 and of $z$ nf238 by in situ hybridization. Representative results of the in situ hybridization stainings are shown in Fig. 1 along with schemes indicating the section levels and the anatomic subdivisions visible in the sections. To facilitate comparison of the expression patterns, Table 1 additionally summarizes expression levels of the examined genes in all expressing brain nuclei and regions.

As shown in Fig. 1 and Table $1, i d 2 b$ transcripts were barely or not detected in our in situ hybridization experiments: we observed only a very weak ubiquitous expression in 1 out of 5 brains investigated (Fig. 1 and data not shown). Therefore, we excluded id2b from further analysis.

At the olfactory bulb/telencephalon junction, we observed that id1 expression is restricted to the ventricular cells of the dorsal telencephalic area (D) (Fig. 1, A1) as previously described (Rodriguez Viales et al., 2015). Also id2a expression is detected along this part of the ventricular layer, and in addition in numerous parenchymal cells (Fig. 1, B1). Id3 is barely detected along the ventricular layer (Fig. 1, D1), and id4 staining is observed in a dorsal and medial periventricular stripe of the dorsal telencephalic area (Fig. 1, E1). On the other hand, the znf238 gene is strongly expressed in a large periventricular stripe in the dorsal telencephalic area and its expression pattern partially overlaps with those of $i d 2 a, i d 3$ and $i d 4$, namely in the periventricular layer (Fig. 1, F1).

More caudally in the telencephalon, id1 staining is detected in the ventricular cells of the ventral and dorsal nuclei of the ventral telencephalon ( $\mathrm{Vv}$ and $\mathrm{Vd}$ ) as well as in the medial (Dm) and lateral (Dl) zone of the dorsal telencephalon (Fig. 1, A2 and A3), as previously reported (Rodriguez Viales et al., 2015). Similarly, id2a staining is also observed in the ventricular cells of the Vv, Vd, Dm and Dl, but also in the Dp (posterior zone of the dorsal telencephalic area) and in the brain parenchyma (Fig. 1, B2 and B3). id3 transcripts are strongly expressed along the ventricle of the subpallium, mainly in the Vv (Fig. 1, D2 and D3), and id4 is barely detectable in the ventricular layer ( $\mathrm{Vv}, \mathrm{Vd}, \mathrm{Dm}$ and $\mathrm{Dl})$, but is strongly expressed in parenchymal cells of the $\mathrm{Vv}$ (Fig. 1, E2 and E3). Interestingly, at this section level, znf238 is mainly (and strongly) expressed in a large periventricular stripe in the Dm, Dl, Dm and Dp (Fig. 1, F2 and F3). In addition, numerous parenchymal cells deep in the $\mathrm{Dl}$ parenchyma express znf238.

In the anterior part of the preoptic area (PPa), numerous id1 and id3 positive cells are detected along the diencephalic ventricular layer (Fig. 1, A3 and D3). This is also the case for id2a, but its expression is not restricted to the ventricular zone, and it is also observed in the parenchyma, in a pattern similar to that of id4 


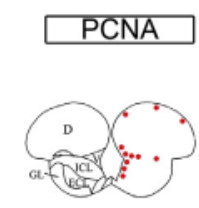

(n):
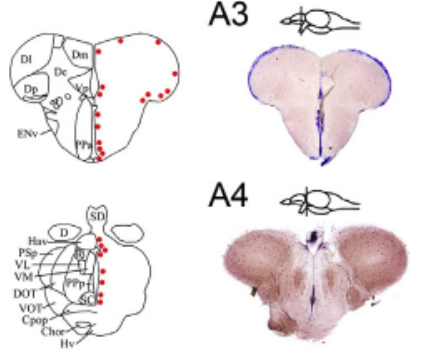

A3

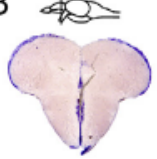

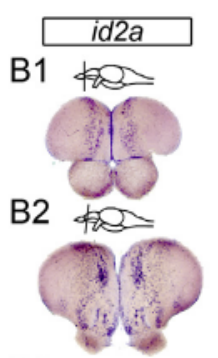

B3

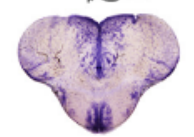

B4 ac
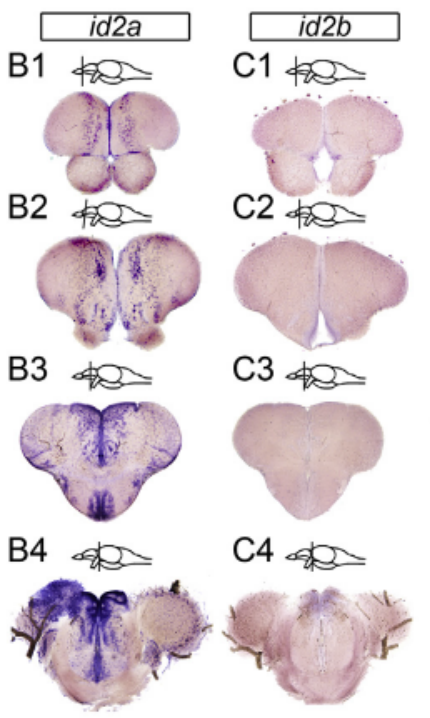

C3

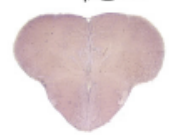

$\mathrm{C} 4$ ar
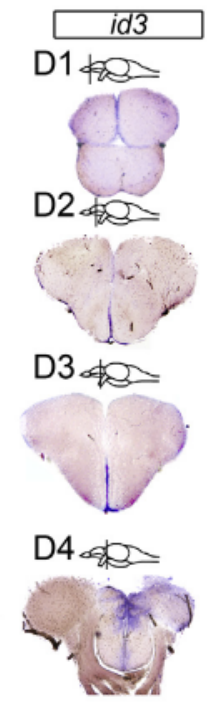

D2

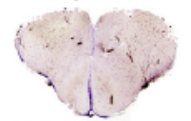

D3

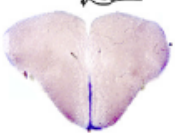

D4 ape
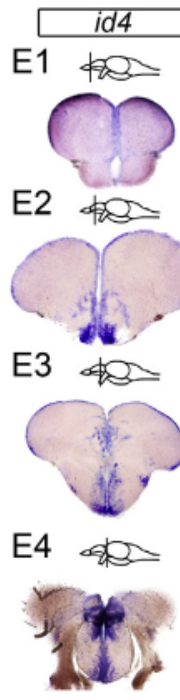

E2

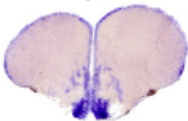

E3

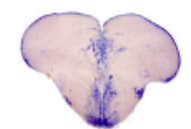

E4 ape

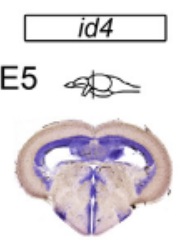

E6

C6 20 -

A6

B6
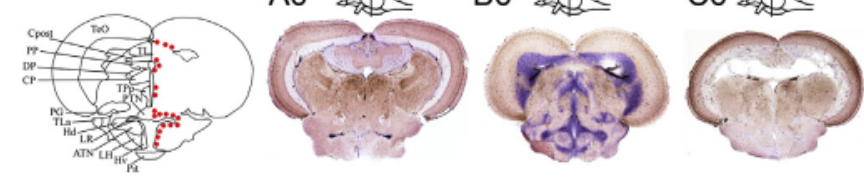

D6 - xd -
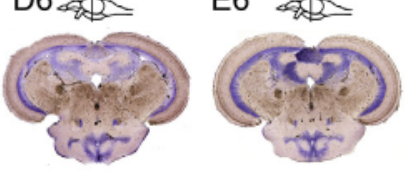

F6

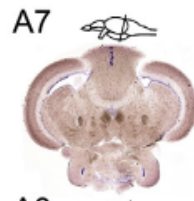

A8 안ㅅ

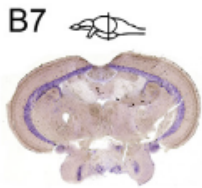

B8 아-

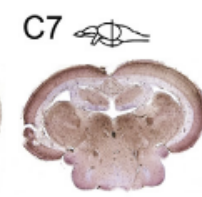

D7 $12=$

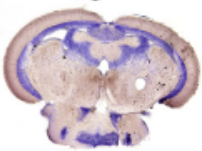

E7 act

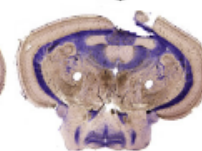

D8 oret
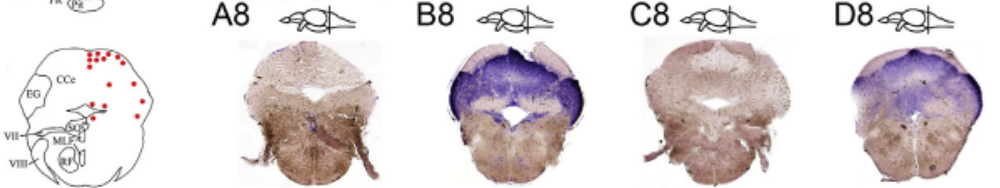

E8

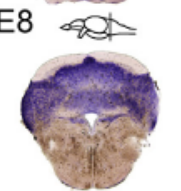

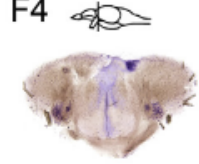
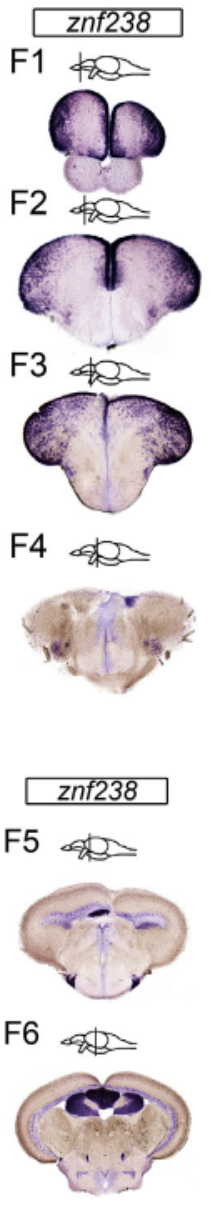

F3 $5=$

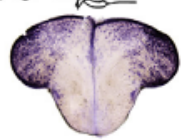

$\mathrm{F} 4$

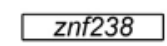

F5 AP

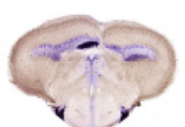

F7 as

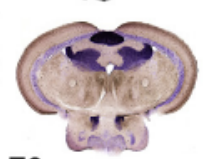

F8 of

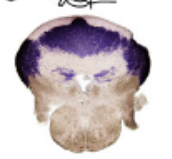

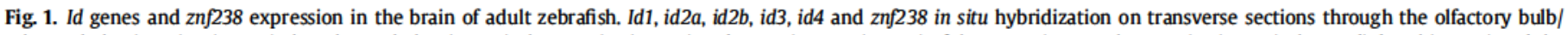

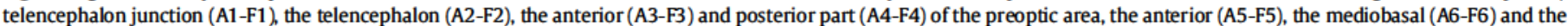

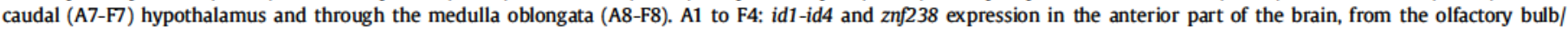

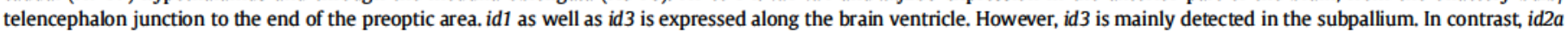

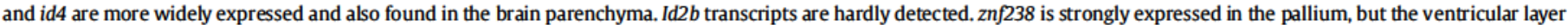

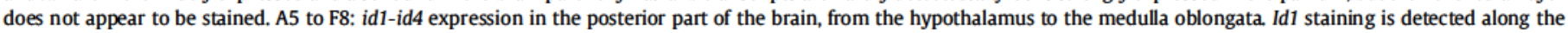

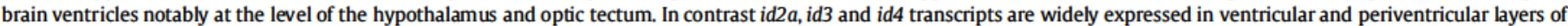

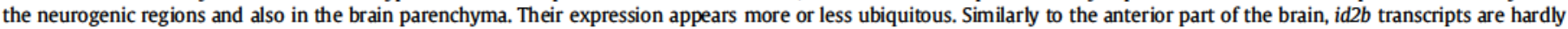

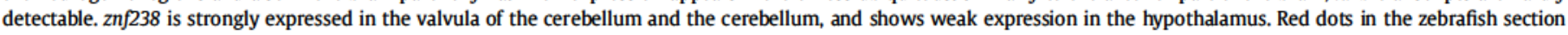
schemes correspond to proliferative areas, which are indicated based on PCNA expression. Bars: $200 \mu \mathrm{m}$ (A1 to F4); $280 \mu \mathrm{m}$ (A8 to F8); $300 \mu \mathrm{m}$ (A5 to F7).

(Fig. 1, B3 and E3). Only a weak znf238 staining is observed in the PPa (Fig. 1, F3).

In the posterior part of the preoptic area (PPp), id1 expression is only detected along the ventricular layer (Fig. 1, A4), while id2a, id3 and id4 are widely expressed in the entire PPp but also in the ventromedial thalamic nucleus (VM) and the habenula (Hav) (Fig. 1, B4, D4 and E4). Znf238 is also widely, if only weakly, expressed in the PPp, VM and Hav (Fig. 1, F4).

More caudally, id1 expression is consistently detected along the ventricular layer of the periglomerular gray zone of the optic tectum ( $\mathrm{TeO}$ ) and of the anterior hypothalamus (Hv), while id2a, id 3 and id4 appear to be widely expressed with a similar distribution in the Hv, zona limitans (ZL), the periventricular nucleus of the posterior tuberculum (TPp), the VM, the thalamus (A), the periventricular gray zone of the $\mathrm{TeO}$ and the anterior preglomerular nucleus (PGa) (Fig. 1, A5, B5, D5 and E5). Znf238 displays a similar pattern, but is only weakly expressed, except in the PGa (Fig. 1, F5).

In more posterior sections, id1 is also detected again in the ventricular layer, along the diencephalic ventricle of the mediobasal hypothalamus, notably in cells surrounding the lateral recess 
Table 1

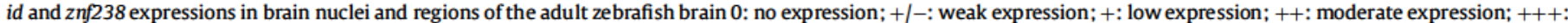
strong expression; $\mathrm{X}$ : no data.

\begin{tabular}{|c|c|c|c|c|c|c|}
\hline Brain regions(according to Wullimann et al., 1996) & id1 & id2a & id $2 b$ & id3 & id4 & $\mathrm{znf} 238$ \\
\hline A, anterior thalamic nucleus & $+1-$ & ++ & 0 & + & ++ & $+1-$ \\
\hline APN, accessory pretectal nucleus & 0 & 0 & 0 & 0 & 0 & 0 \\
\hline ATN, anterior tuberal nucleus & + & + & 0 & + & + & 0 \\
\hline CCe, corpus cerebelli & $+1-$ & +++ & 0 & $+1-$ & +++ & +++ \\
\hline Chab, habenular commissure & 0 & 0 & 0 & 0 & 0 & 0 \\
\hline Chor, horizontal commissure & 0 & 0 & 0 & 0 & 0 & 0 \\
\hline $\mathrm{CM}$, corpus mamillare & 0 & + & 0 & ++ & ++ & +++ \\
\hline $\mathrm{CP}$, central posterior thalamic nucleus & 0 & $+1-$ & 0 & 0 & 0 & 0 \\
\hline CPN, central pretectal nucleus & 0 & 0 & 0 & 0 & 0 & 0 \\
\hline Cpop, postoptic commissure & 0 & 0 & 0 & 0 & 0 & 0 \\
\hline Cpost, posterior commissure & 0 & 0 & 0 & 0 & 0 & 0 \\
\hline D, dorsal telencephalic area & + & ++ & 0 & $+1-$ & ++ & +++ \\
\hline Dc, central zone of dorsal telencephalic area & 0 & $+1-$ & 0 & 0 & 0 & + \\
\hline Dl, lateral zone of dorsal telencephalic area & + & 0 & $+1-$ & $+1-$ & + & +++ \\
\hline Dm, medial zone of dorsal telencephalic area & + & ++ & 0 & $+1-$ & + & +++ \\
\hline DOT, dorsomedial optic tract & 0 & $+1-$ & 0 & 0 & $+1-$ & $+1-$ \\
\hline Dp, posterior zone of dorsal telencephalic area & ++ & ++ & 0 & $+1-$ & + & +++ \\
\hline DP, dorsal posterior thalamic nucleus & 0 & + & 0 & 0 & 0 & 0 \\
\hline ECL, external cellular layer of olfactory bulb & 0 & 0 & 0 & 0 & 0 & 0 \\
\hline EG, eminentia granularis & 0 & +++ & 0 & + & +++ & +++ \\
\hline ENv, entopendoncular nucleus, ventral part & 0 & ++ & 0 & 0 & ++ & + \\
\hline FR, fasciculus retroflexus & 0 & $+1-$ & 0 & 0 & 0 & 0 \\
\hline GL, glomerular layer of olfactory bulb & 0 & ++ & 0 & 0 & 0 & 0 \\
\hline Had, dorsal habenular nucleus & $\mathrm{x}$ & $\mathrm{X}$ & $\mathrm{x}$ & $\mathrm{X}$ & $\mathrm{X}$ & $\mathrm{x}$ \\
\hline Hav, ventral habenular nucleus & 0 & +++ & $+1-$ & ++ & +++ & 0 \\
\hline Hc, caudal zone of periventricular hypothalamus & + & + & 0 & +++ & +++ & + \\
\hline Hd, dorsal zone of periventricular hypothalamus & ++ & +++ & 0 & +++ & +++ & + \\
\hline Hv, ventral zone of periventricular hypothalamus & + & +++ & 0 & +++ & +++ & $+1-$ \\
\hline ICL, internal cellular layer of olfactory bulb & 0 & 0 & 0 & 0 & 0 & 0 \\
\hline IL, inferior lobe & 0 & $+1-$ & 0 & $+1-$ & $+1-$ & $+1-$ \\
\hline LH, lateral hypothalamic nucleus & 0 & +++ & 0 & ++ & +++ & $+1-$ \\
\hline LLF: lateral longitudinal fascicle & 0 & $+1-$ & 0 & $+1-$ & ++ & 0 \\
\hline $\mathrm{LR}$, lateral recess of diencephalic nucleus & $\mathrm{X}$ & $\mathrm{x}$ & $\mathrm{X}$ & $\mathrm{X}$ & $\mathrm{X}$ & $\mathrm{X}$ \\
\hline MLF, medial longitudinal fascicle & 0 & 0 & 0 & 0 & 0 & 0 \\
\hline NMLF, nucleus of medial longitudinal fascicle & 0 & 0 & 0 & 0 & 0 & 0 \\
\hline PG, preglomerular nucleus & 0 & 0 & 0 & 0 & 0 & 0 \\
\hline PGa, anterior preglomerular nucleus & 0 & +++ & 0 & +++ & +++ & +++ \\
\hline PGI, lateral preglomerular nucleus & 0 & +++ & 0 & +++ & +++ & +++ \\
\hline Pit, pituitary & $\mathrm{X}$ & $\mathrm{X}$ & $\mathrm{X}$ & $\mathrm{X}$ & $\mathrm{X}$ & $\mathrm{X}$ \\
\hline PO, posterior pretectal nucleus & 0 & $+1-$ & 0 & 0 & 0 & 0 \\
\hline $\mathrm{PP}$, periventricular pretectal nucleus & 0 & ++ & 0 & ++ & +++ & $+1-$ \\
\hline PPa, parvocellular preoptic nucleus, anterior part & ++ & +++ & 0 & ++ & +++ & $+1-$ \\
\hline PPp, parvocellular preoptic nucleus, posterior part & ++ & +++ & 0 & $+1-$ & +++ & $+1-$ \\
\hline $\mathrm{PR}$, posterior recess of diencephalic ventricle & $\mathrm{X}$ & $\mathrm{X}$ & $\mathrm{X}$ & $\mathrm{X}$ & $\mathrm{X}$ & $\mathrm{X}$ \\
\hline PSp, parvocellular superficial pretectal nucleus & 0 & $+1-$ & 0 & 0 & 0 & $+1-$ \\
\hline PTN, posterior tuberal nucleus & 0 & ++ & 0 & ++ & ++ & $+1-$ \\
\hline$R$, rostrolateral nucleus & 0 & $+1-$ & 0 & $+1-$ & $+1-$ & 0 \\
\hline RF, reticular formation & 0 & $+1-$ & 0 & 0 & 0 & 0 \\
\hline SC, suprachiasmatic nucleus & $+1-$ & +++ & 0 & $+1-$ & +++ & $+1-$ \\
\hline SD, saccus dorsalis & $+1-$ & $\mathrm{X}$ & $\mathrm{X}$ & $\mathrm{x}$ & $\mathrm{X}$ & $\mathrm{X}$ \\
\hline So, secondary octaval population & $+1-$ & 0 & 0 & 0 & 0 & 0 \\
\hline TeO, tectum opticum & + & +++ & 0 & +++ & +++ & $+1-$ \\
\hline $\mathrm{TL}$, torus longitudinalis & 0 & + & 0 & ++ & ++ & $+1-$ \\
\hline TLa, torus lateralis & 0 & $+1-$ & 0 & $+1-$ & $+1-$ & $+1-$ \\
\hline TPp, periventricular nucleus of posterior tuberculum & 0 & ++ & 0 & 0 & 0 & 0 \\
\hline TS, torus semicircularis & 0 & + & 0 & 0 & 0 & 0 \\
\hline $\mathrm{V}$, ventral telencephalic area & + & ++ & 0 & + & ++ & ++ \\
\hline V3, third ventricle & $\mathrm{x}$ & $\mathrm{x}$ & $\mathrm{X}$ & $\mathrm{X}$ & $\mathrm{X}$ & $\mathrm{X}$ \\
\hline VII, sensory root of the facial nerve & 0 & 0 & 0 & 0 & 0 & \\
\hline VIII, octaval nerve & 0 & 0 & 0 & 0 & 0 & 0 \\
\hline VCe, valvula cerebelli & 0 & 0 & 0 & +++ & +++ & +++ \\
\hline Vd, dorsal nucleus of ventral telencephalic area & + & + & 0 & + & ++ & 0 \\
\hline VL, ventrolateral thalamic nucleus & 0 & ++ & $+1-$ & 0 & +++ & $+1-$ \\
\hline VM, ventromedial thalamic nucleus & 0 & ++ & $+1-$ & 0 & +++ & $+1-$ \\
\hline VOT, ventrolateral optic tract & 0 & 0 & 0 & 0 & 0 & 0 \\
\hline Vp, postcommissural nucleus of ventral telencephalic area & + & +++ & 0 & 0 & ++ & $+1-$ \\
\hline Vv, ventral nucleus of dorsal telencephalic area & + & ++ & 0 & ++ & +++ & 0 \\
\hline ZL, zona limitans. & $+1-$ & + & 0 & $+1-$ & $+1-$ & 0 \\
\hline
\end{tabular}

(LR) (Fig. 1, A6). The other id genes, except id2b that is not detected, exhibit an overall similar expression pattern, showing a broad expression in the $\mathrm{Hv}$ around the LR and also in the periglomerular grey zone of the TeO(Fig. 1, B6, D6 and E6).Znf238 displays a similar pattern of expression, but the staining is weaker in these regions than that of the id genes (Fig. 1, F6). 
In addition, id 1 is consistently expressed in the ventricular cells lining the LR and posterior recess (PR) of the hypothalamus and in the ventricular zone of the periglomerular gray zone of the $\mathrm{TeO}$. A weak id1 expression is also observed in the cerebellum (Fig. 1, A7). Again, id2a, id3 and id4 exhibit a similar expression pattern such as in the caudal hypothalamus and the valvula of the cerebellum (VCe). In these regions, znf 238 pattern is similar to those of $i d 2 a$, id 3 and id4 (Fig. 1, B7, D7, E7 and F7).

Finally, id 1 is detected along the rhombencephalic ventricle while id $2 a, i d 3, i d 4$ and $z n f 238$ are also detected in the periventricular layer of the rhombencephalic ventricle as well as in the cerebellum (CCe) (Fig. 1, A8-F8).

In summary, all $i d$ genes with the exception of $i d 2 b$ were found to be specifically expressed in the zebrafish adult brain, as was their potential negative regulator $z n f 238$. id1 is detected only in the ventricular cells across the whole brain and in few cells of the cerebellum (Fig. 1, A1-A8). The other id genes show a different type of distribution: In the anterior part of the brain (from the olfactory bulb/telencephalon junction to the PPa),id2a, id3 and id4 exhibit specific patterns of expression with only a few overlapping areas such as the ventricular zone of the Vv/Vd or the PPa. In contrast, from the PPp to the cerebellum, id2a, id3, id4 and znf238 display almost identical expression patterns, while id1 remains restricted to the ventricular cells. Interestingly, and potentially consistent with a negative cross-regulation of expression between znf 238 and the ids, their expression levels sometimes show a negative correlation. Thus, id genes are weakly detected in the D, Dl and Dm, while zmf238 is highly expressed in these regions. In contrast, id genes are strongly detected in the $\mathrm{Vd}, \mathrm{Vv}, \mathrm{PPa}, \mathrm{PPp}$ and $\mathrm{TeO}$ whereas znf238 is weakly expressed in these regions. However, we also noticed regions that display high levels of both znf238 and id expression, such as the PGa and PGl, suggesting that here the negative cross regulation may be overridden by other factors (Table 1). Strikingly, all four id genes present in the brain as well as znf238 are expressed in well-known proliferative/neurogenic regions, such as the ventricular and periventricular layers of the telencephalic ventricle and in the hypothalamus where the lateral recess of the diencephalic ventricle starts to open (Grandel et al., 2006; Lindsey and Tropepe, 2006; Pellegrini et al., 2007) (Fig. 1, schemes in the left column with PCNA-positive cells indicated by red dots).

\subsection{Characterization of id-expressing cells in the telencephalon}

Given that the telencephalon contains the homologues of the mammalian adult neurogenic regions, making this the preferred subdivision of the brain targeted in zebrafish neurogenic and neural regeneration studies, we decided to examine which cell types express id genes in the telencephalon, by performing costainings with markers for the different subtypes of neural progenitors. Along the ventricular zone of the adult zebrafish telencephalon, three main types of neural progenitor cells have been defined by characteristic marker combinations: type 1 cells, corresponding to quiescent radial glial cells (S100 $\beta$-positive and PCNAnegative); type 2 cells, corresponding to proliferative radial glial cells (S100 $\beta$ and PCNA-positive); and type 3 cells which are believed to be actively dividing neuroblasts $(\mathrm{S} 100 \beta$-negative and PCNA-positive) and constitute non radial glial progenitors (März et al., 2010). These latest progenitors are mainly found in the rostral migratory stream like region (RMS). Thus, we characterized id-expressing cells by performing fluorescent in situ hybridization against each of the four selected id genes, followed by immunohistochemistry against $\mathrm{S} 100 \beta / \mathrm{PCNA}$ or the panneuronal marker HuC/D (Figs. 2-4).
To examine id1 expression in detail we made use of the transgenic line $\mathrm{Tg}$ (id1:EGFP) (Rodriguez Viales et al., 2015). This reporter line has been shown to closely mimic endogenous id1 mRNA expression. Consistent with previous findings (Rodriguez Viales et al., 2015), transgene expression driven by id1 regulatory regions was detected in radial glial cells (Fig. 2A-L). In the Dm, we observed $\mathrm{Tg}$ (id1:EGFP) expression in type 1 cells (Fig. $2 \mathrm{E}-\mathrm{H}$, arrows), while expression in type 2 progenitors was only low or not detected (Fig. $2 \mathrm{E}-\mathrm{H}$, arrowheads). In the RMS-like region, which is composed of type 3 progenitors, we did not detect expression of Tg(id1:EGFP) (Fig. 2I-L, asterisks).

Id2 a mRNAs were widely expressed in the brain, notably along the ventricular layer and in the brain parenchyma of the $\mathrm{Dl}, \mathrm{Dm}, \mathrm{Vd}$ and $\mathrm{Vv}$ (Figs. 1 and 2). In the Dm, id2a transcripts were detected in type 1 (Fig. 2Q-T, arrows) and type 2 progenitors (Fig. 2Q-T, arrowheads). In the RMS, we also observed that type 3 progenitors strongly express $i d 2 a$ (Fig. $2 \mathrm{U}-\mathrm{X}$, asterisks).

Although id3 staining was only detected in the subpallium with colorimetric ISH (Fig. 1 D2), we also detected a weak id3 staining in the pallium (Dm and Dl) with fluorescent labelling (Fig. $3 \mathrm{~A}-\mathrm{H}$ ), probably because the fluorescent ISH is more sensitive than the colorimetric one used in Fig. 1. In the medial ventricular zone of the pallium (Fig. 3E-H), type 1 (arrow) and 2 progenitors (arrowhead) exhibit a very weak $i d 3$ staining (Fig. $3 \mathrm{H}$, see high squares boxes 1 and 2). In the RMS (lower box in Fig. 3D), a strong id3 staining is observed at the level of type 3 cells (Fig. 3I-L, asterisks).

Finally, with the exception of the parenchymal cells which widely expressed id4, we did not observe any obvious id4 expression in type 1 (arrows) and type 2 cells (arrowheads) in the Dm, as well as in type 3 cells (asterisks) in the RMS (Fig. 3M-X).

To further characterize id-expressing cells in the telencephalon, we also investigated id genes expression in HuC/D-positive neurons because of the known role of ids in neuronal differentiation/specification (Tzeng, 2003). Numerous id2a, id 3 and id4-expressing cells in the parenchyma correspond to HuC/D-positive neurons (Fig. 4D-L, arrows), while id1 was never co-expressed with this neuronal marker (Fig. 4A-C). This suggests that, in contrast to id1, id2-4 might play a role in neuronal differentiation.

Taken together, our data show that a) id1 expression is mainly restricted to type 1 cells, b) id2a is detected in type 1,2 and 3 cells as well as in neurons, c) id3 transcripts are strongly expressed in type 3 progenitors and weakly in radial glial cells and neurons, and finally 4) id4 is mainly detected in neurons The overlapping expression in some progenitors (id1 and id $2 a$ in type 1 and 2 cells; id $2 a$ and $i d 3$ in type 3 cells) may be consistent with some redundancy of Id function in these cell types.

\section{3. $z n f 238$ gene expression in id-expressing cells and neurons in the adult zebrafish brain}

Rp58, the product of $z n f 238$, was shown to negatively regulate Id expression in mammals, and we observed that the expression levels of $i d$ genes and $z n f 238$ show opposite tendencies in some areas of the adult zebrafish brain (Fig. 1 and Table 1). Therefore, we examined a) whether the same cell types shown to express id genes also express $z n f 238$, and b) whether $z n f 238$ is indeed co-expressed with id genes in these cells. $z \mathrm{nf} 238$ is not expressed in the ventricular S100ß-positive radial glial cells (Fig. 5A-I), and we also do not observe znf238 in the RMS region (data not shown). Thus, $z n f 238$ is not expressed in any of the three neural progenitor cell types. In contrast, numerous HuC/D-positive neurons strongly express znf238 (Fig. 5J-L). In line with these observations, we show that znf238 is co-expressed within many id2a, id 3 and id4-positive cells localized in the brain parenchyma, but not along the ventricular surface, again indicating that it is only expressed in neurons. 

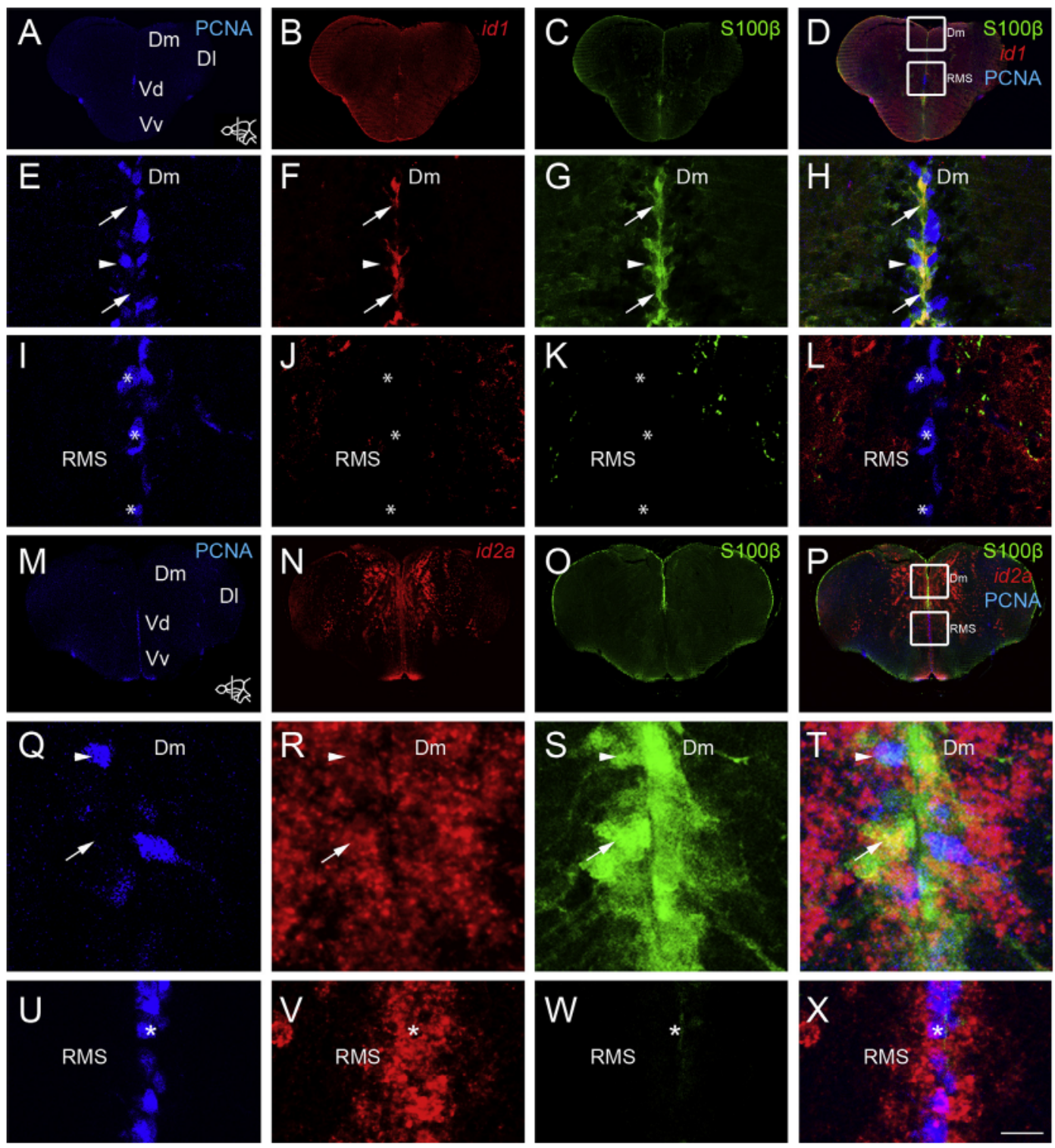

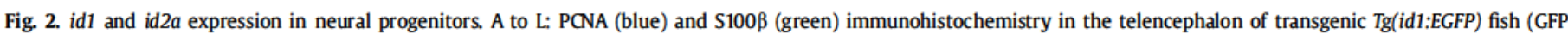

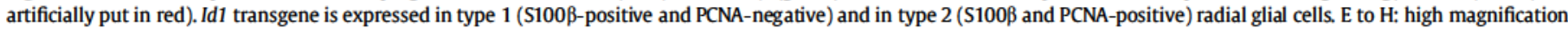

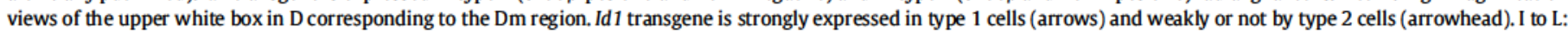

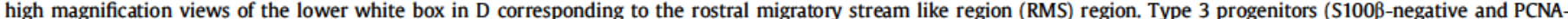

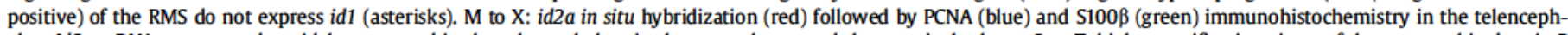

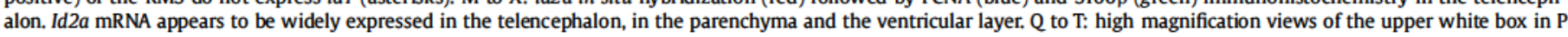

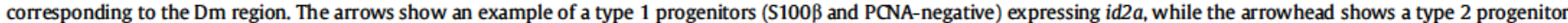

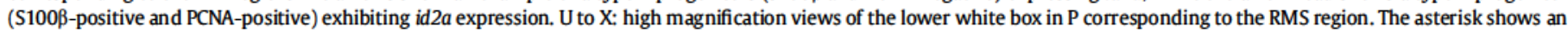

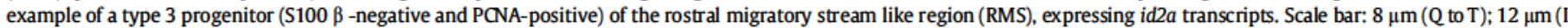
to $\mathrm{L}$ ); $20 \mu \mathrm{m}$ (U to X); $25 \mu \mathrm{m}$ (E to H); $250 \mu \mathrm{m}$ (A to D); $310 \mu \mathrm{m}$ (M to P).

Consistently, we do not observe co-expression of id1 and znf 238 in the ventricular zone (Fig. 6).

\section{Discussion}

Id proteins play key roles in embryonic and adult neurogenesis, as shown in mammals, birds and more recently in adult zebrafish for Id1 (Bai et al., 2007; Jen et al., 1997; Liu et al., 2013; Lyden et al., 1999; Nam and Benezra, 2009; Riechmann and Sablitzky, 1995; Rodriguez Viales et al., 2015; Sugimori et al., 2007). In this study, we have (a) characterized the expression of $i d$ and $z n f 238$ genes in the whole brain of zebrafish, (b) highlighted their overlapping distribution and their expression in neurogenic niches. Detailed expression analysis in neural progenitors of the telencephalon revealed patterns of id expression that are consistent with a potential redundancy of Id function in these cells (Fig. 7).

\subsection{Id genes expression in the whole brain}

Our data show that id1,id2a, id3 and id4 are widely expressed within the entire brain of adult zebrafish, while $i d 2 b$ is barely detectable, in agreement with RNAseq data (Armant et al., 2013; Diotel et al., 2015). Thus, we present new data showing that id1expressing cells are not limited to the telencephalon (Rodriguez 

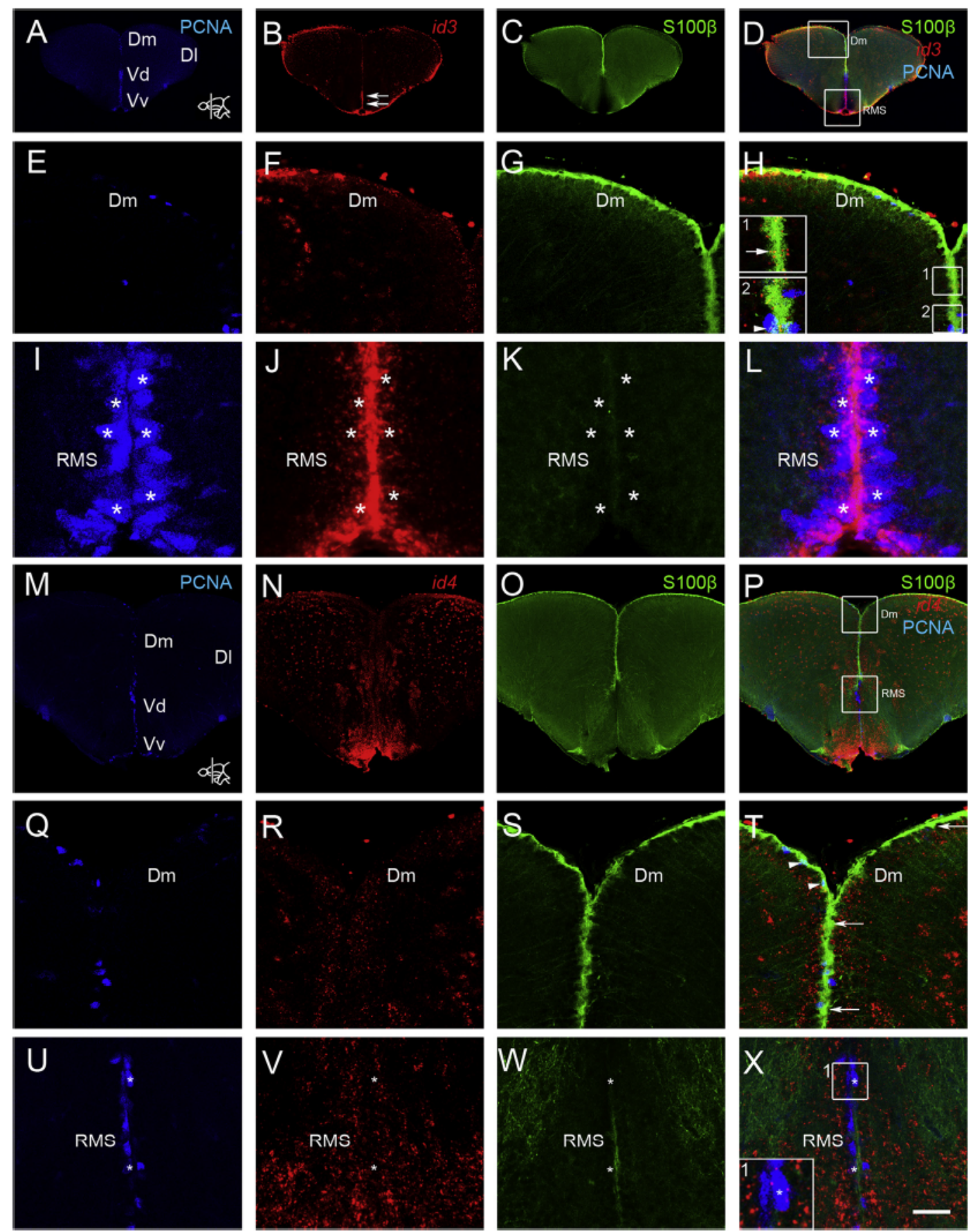

Fig. 3. Strong id3 expression in type 3 progenitors and weak id 4 expression in neural progenitors. A to L: id 3 in situ hybridization (red) followed by PCNA (blue) and S100 $\beta$ (green) immunohistochemistry in the telencephalon. Id 3 appears to be mainly and strongly expressed in the ventricular layer of the subpallium. $\mathrm{E}$ to $\mathrm{H}$ : high magnification views of the upper white box in D corresponding to the Dm region. A weak id3 expression is detected in non-proliferative (arrow) and proliferative (arrowhead) S100B-positive radial glial cells (type 1 and type 2 cells, respectively). I to L: high magnification views of the lower white box in D corresponding to the rostral migratory stream like region (RMS) region. The asterisks show a strong id 3 expression in type 3 progenitors (S100ß-negative and PCNA-positive) of the RMS. M to X: id 4 in situ hybridization (red) followed by PCNA (blue) and $S 100 \beta$ (green) immunohistochemistry in the telencephalon. id4 expression appears to be widely expressed in the parenchyma but not in the ventricular layer. $Q$ to $\mathrm{T}$ : high magnification views of the upper white box in D corresponding to the Dm region. id4 transcripts are mainly absent from non-proliferative (arrow) and proliferative (arrowhead) S100ß-positive radial glial cells (type 1 and type 2 cells, respectively). U to X: high magnification views of the lower white box in Pcorresponding to the RMS region. In the RMS, id4 expression is barely detected in type 3 progenitor (S100ß-negative and PCNA-positive) as shown with asterisks. Scale bar: $15 \mu \mathrm{m}$ (I to L); $20 \mu \mathrm{m}$ (U to X); $35 \mu \mathrm{m}(\mathrm{Q}$ to T); $40 \mu \mathrm{m}$ (E to $\mathrm{H}$ ); $130 \mu \mathrm{m}$ (M to P); $250 \mu \mathrm{m}$ (A to D).

Viales et al., 2015), but can also be found in the ventricular zone of the diencephalon (i.e. preoptic area and hypothalamus), the mesencephalon (periglomerular gray zone of the optic tectum), and in cells lining the rhombencephalic ventricle. Interestingly, expression always remains restricted to the ventricular cells. Given the well-established role of Id1 in mammalian neurogenesis (Bai et al., 2007; Lyden et al., 1999; Nam and Benezra, 2009; Tzeng and de Vellis, 1998) and its recently described function in the control of stem cell proliferation in the zebrafish telencephalon (Rodriguez Viales et al., 2015), these data suggest a potential 

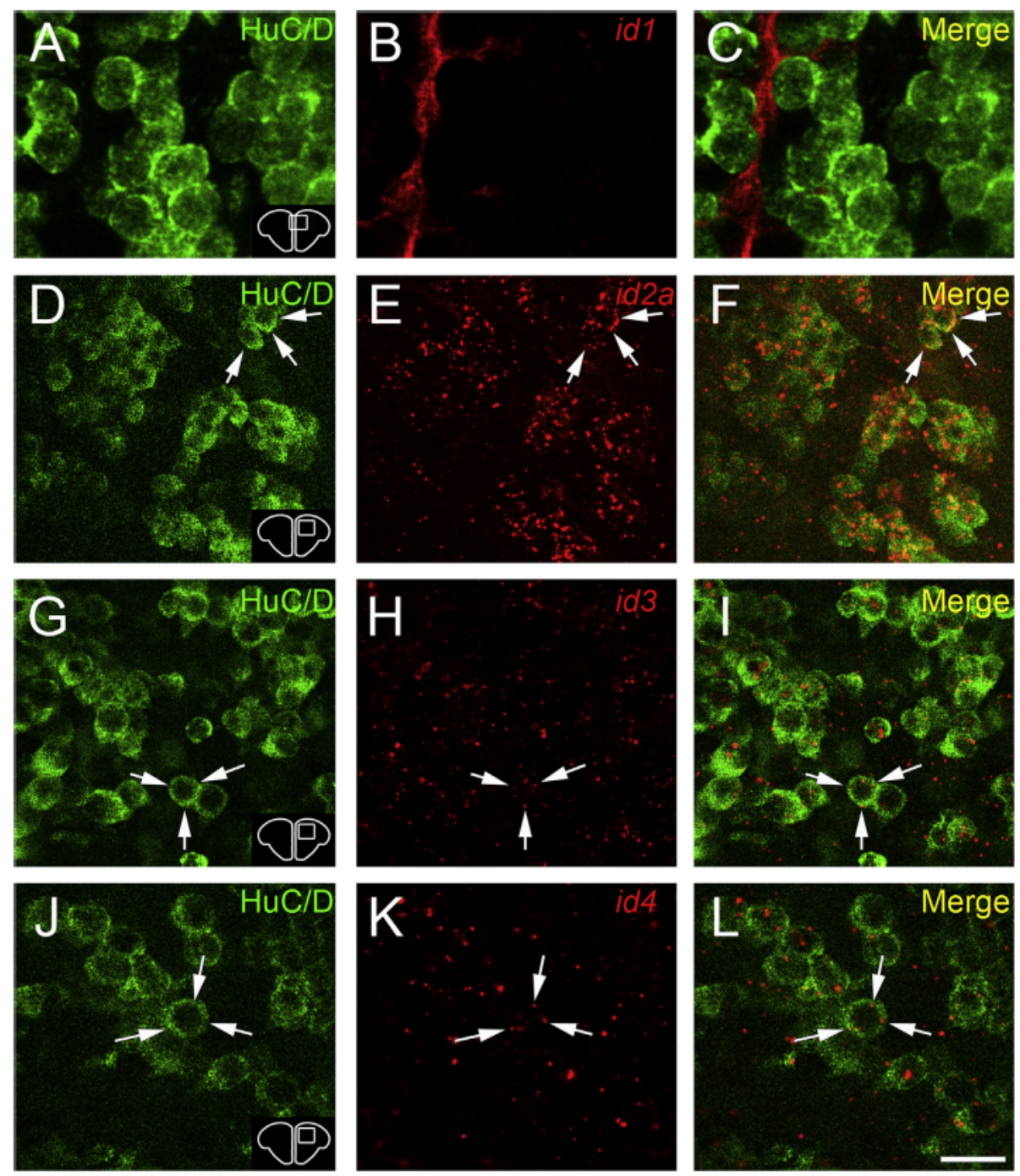

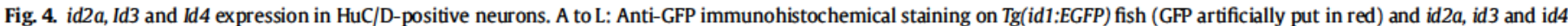

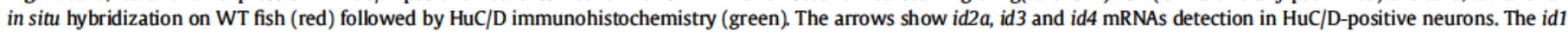
transgene is not detected in neurons. Scale bar: $7 \mu \mathrm{m}$ (A to C); $16 \mu \mathrm{m}$ (D to I); $11 \mu \mathrm{m}$ (J to L).

involvement also in midbrain and hindbrain neurogenesis. Importantly, in contrast to id1, the other id transcripts appear not to be restricted to the ventricular zone. Also, they exhibit distinct and specific gene expression patterns in the anterior part of the brain (i.e., from the olfactory bulb/telencephalon junction to the PPa), while they show a strong overlapping expression in the mes-, met and rhombencephalon. However, also some regions of the telencephalon express all id genes including id1, notably the Dp, which has been suggested to be the homologue of the mammalian hippocampus.

In rodents, Id genes are also widely expressed in the brain. Id 1 is mainly detected in the dentate gyrus of the hippocampus and in the SVZ of the lateral ventricles, while Id2-4 are also detected in the olfactory areas, the isocortex, the thalamus, the hypothalamus and the cerebellum (Kitajima et al., 2006; Lau et al., 2008; Lee et al., 2015; Nam and Benezra, 2009; Ng et al., 2009; Tzeng and de Vellis, 1998). It consequently appears that id expression in the brain is relatively well conserved between fish and rodents.

\section{Id gene expression in neural progenitors}

Focussing on the well-characterized telencephalon, we show that (a) id 1 is expressed in type 1 and 2 progenitors (as previously described (Rodriguez Viales et al., 2015)), (b) id2a is detected in type 1, 2 and 3 cells as well as in neurons across the parenchyma of the entire telencephalon, (c) id3 is mainly observed in type 3 progenitors and neurons, while (d) id4 is mainly detected in postmitotic neurons of the pallium (Figs. 2-4 and Fig. 7). With these data, we provide the first comprehensive description of id gene expression in adult neural progenitors in zebrafish. Our results suggest that other id genes in addition to id1 could be involved in the activity of neural progenitors, and that some redundancy in Id function and/or compensatory mechanisms could be present in neural stem cells, as described in mammals and chick for Id1 and Id3 (Bai et al., 2007). This could apply particularly to the pairs of id1/ $i d 2 a$ and $i d 2 a / i d 3$, which are strongly expressed in type 1 and type 3 progenitors, respectively. Interestingly, in the rodent brain, Id 1 and Id3 appear to be preferentially expressed in progenitor cells while Id2 and Id4 persist in post-mitotic neurons (Hirai et al., 2012; Jen et al., 1997; Neuman et al., 1993; Riechmann and Sablitzky, 1995; Tzeng and de Vellis, 1998; Yokota, 2001), similar to what we observe in fish. In addition, in the mouse SVZ, Id1 has been shown to be strongly expressed in a rare population of astrocytes displaying stem cell properties (Nam and Benezra, 2009) that could be the equivalent of type 1 cells in zebrafish. Furthermore, id2a expression in neural progenitors of the telencephalon strongly 

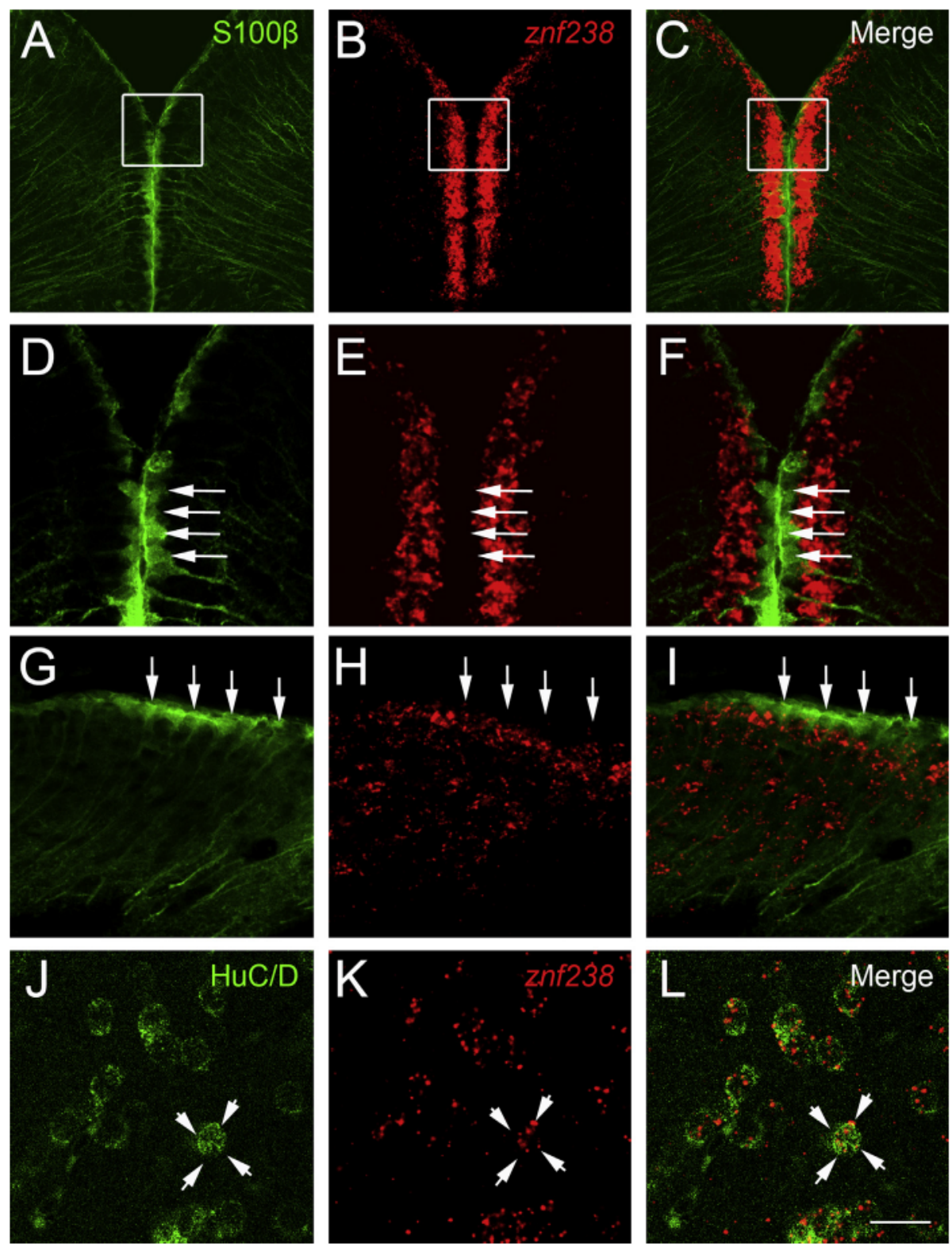

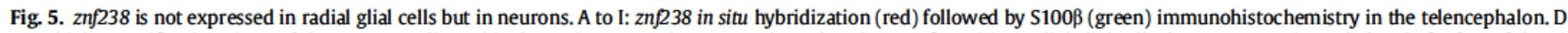

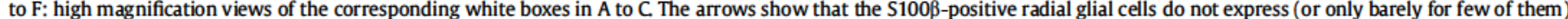

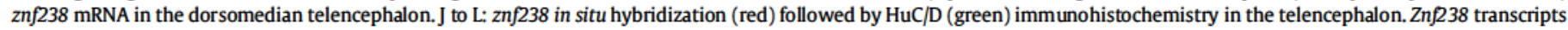
were detected in HuC/D-positive neurons (arrows) Scale bar: $12 \mu \mathrm{m}$ (J to L); $20 \mu \mathrm{m}$ (D to I); $70 \mu \mathrm{m}$ (A to C).
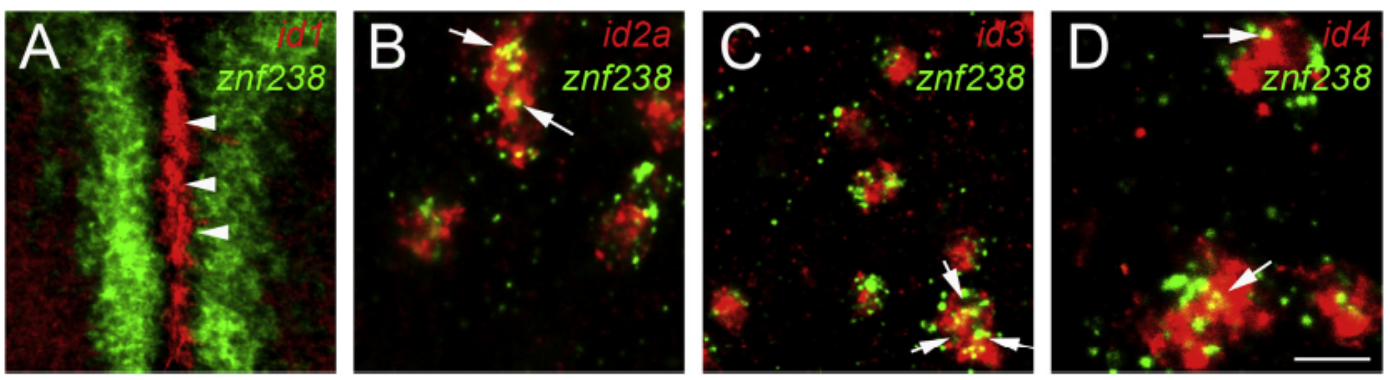

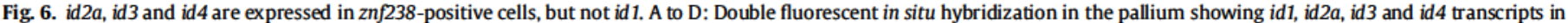

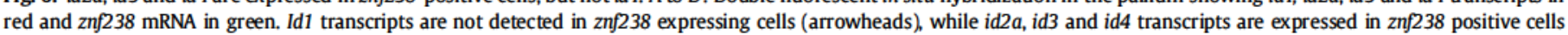
(arrows). Scale bar: $6 \mu \mathrm{m}$ (D); $12 \mu \mathrm{m}$ (B to C); $35 \mu \mathrm{m}$ (A). 


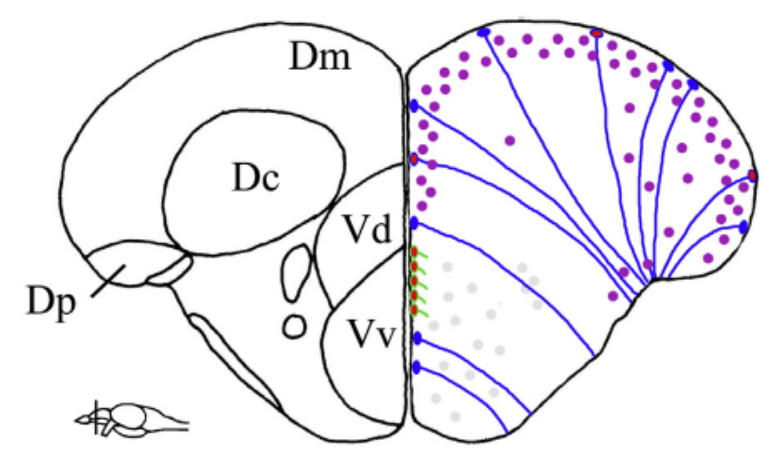

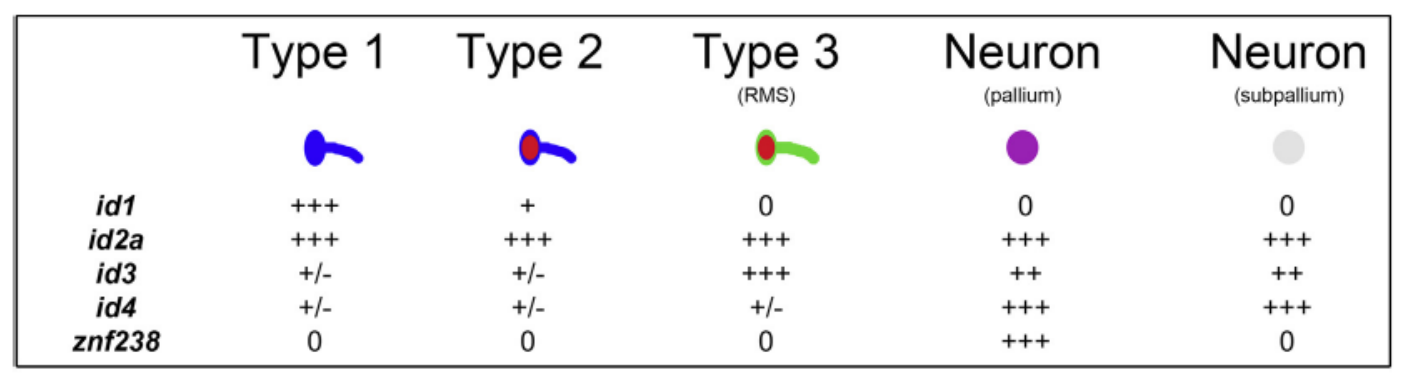

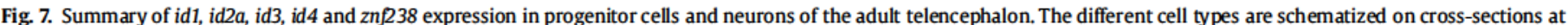

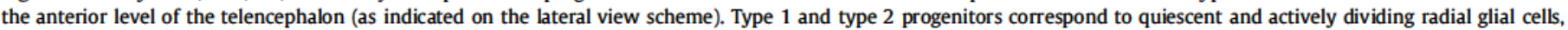

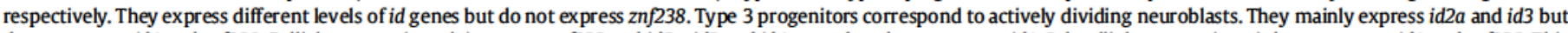

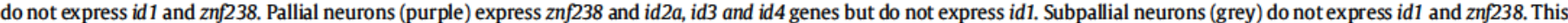

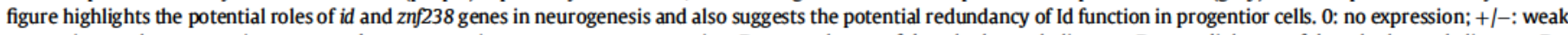

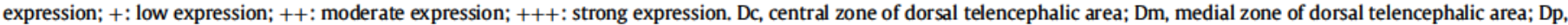
posterior zone of dorsal telencephalic area; Vd, dorsal nucleus of ventral telencephalic area; Vv, ventral nucleus of dorsal telencephalic area.

suggests its involvement in telencephalic neurogenesis. Interestingly, id $2 a$ was shown to regulate retinoblast proliferation and differentiation during zebrafish retinogenesis by modulation of the Notch pathway activity (Uribe and Gross, 2010; Uribe et al., 2012), and it is tempting to speculate that it might have analogous functions in the regulation of neural progenitors. Evidence from mammals indicates that Id2 is required for dopaminergic neuronal specification during adult olfactory neurogenesis (Havrda et al., 2008), and that it functions as a pro-proliferative gene for neural progenitor cells (Paolella et al., 2011).

Taken together, these data strongly suggest key roles of Id proteins in neurogenic activity in the brain of adult zebrafish, as well as potential redundancy (Fig. 7).

\subsection{Znf238 expression in the brain: correlation with id distribution}

In rodents, $Z n f 238$ expression is detected in the neocortex, the hippocampus, parts of the amygdala and in granular cells of the cerebellum (Ohtaka-Maruyama et al., 2007). In Rp58 knock-out mice, Id members are ectopically expressed in the ventricular and subventricular zone (Hirai et al., 2012). This shows that Rp58 is an important factor driving the correct expression of id members and controlling neural stem cell proliferation in the developing cortex of mammals (Hirai et al., 2012).

In zebrafish, our investigations show that the $z n f 238$ is also widely expressed in the brain, both in the telencephalon as recently described (Diotel et al., 2015) and also in the remaining parts of the brain. Znf238 is co-expressed with id2a, id 3 and $i d 4$ in numerous parenchymal pallial cells (Figs. 6 and 7). In contrast, no coexpression was detected with id 1 nor with $\mathrm{S} 100 \beta$, which both label radial glia cells (type 1 and/or type2). Interestingly, in the adult telencephalon, the ventricular layer of the pallium is surrounded by a broad znf238-positive periventricular stripe. Given that id1 and $z n f 238$ are not co-expressed, znf238 could participate in the restriction of id1 expression to the ventricular cells of the pallium, inhibiting its expression outside of the ventricular zone. In addition, some regions strongly expressing znf238 appear to barely express id genes, such as the dorsal telencephalic area (Fig. 1, row A1-F1) and the dorsolateral domain of the telencephalon (Fig. 1, rows A2-F2 and A3-F3). In contrast, regions that do not express znf38, or show very weak expression, generally strongly express id genes, notably the preoptic area (PPa and PPp) and the habenula (Fig. 1, rows A3-F3 and A4-F4), the optic tectum and also the ventricular and periventricular regions of the hypothalamus (Fig. 1, A5F7). These data argue in favour of a potential regulation of $i d$ genes by $z n f 238$. However, in other regions, such as in the valvula of the cerebellum (VCe) and the cerebellum, strong expression of both znf238 and id2a, id 3 and id4 is observed, showing that there is no strict mutually exclusive expression of the two gene groups, and indicating that other, unknown regulators may influence their expression patterns.

\subsection{Conclusions}

To conclude, our work provides a detailed expression of $i d$ and znf238 genes in the adult zebrafish brain. It suggests important roles for id and znf238 genes in the control of neural progenitor proliferation and neuronal cell-specification in the whole brain including the telencephalon, the preoptic area, the hypothalamus and the cerebellum. Our work is a first step towards more comprehensive studies concerning the role of Id proteins in adult neurogenesis in zebrafish and their potential regulation by znf 238 and other factors. 


\section{Experimental procedure}

\subsection{Zebrafish strains and maintenance}

Fish were maintained under standard conditions of photoperiod (14-h light/10-h dark) and temperature $\left(28.5^{\circ} \mathrm{C}\right)$ in recirculation systems (Schwarz Ltd Germany, Müller and Pfleger Ltd Germany), and fed with commercial food as previously described (Westerfield, 2007). Experiments were performed on 3-6 month old adult zebrafish of the $\mathrm{AB}$ wildtype strain or of the $\mathrm{Tg}$ (id1:EGFP) reporter line (Rodriguez Viales et al., 2015). Experiments on animals were performed in accordance with the German animal protection standards and were approved by the Government of BadenWurttemberg, Regierungspräsidium Karlsruhe, Germany (Aktenzeichen 35-9185.81/G-272/12 'Adulte Neurogenese').

\subsection{Dissection and fixation}

Fish were anesthetized in $0.02 \%$ tricaine methanesulfonate (MS222, Sigma, pH7) before being sacrificed in ice water (Westerfield, 2007 ) and fixed in $4 \%$ paraformaldehyde in phosphate-buffered saline (PBS, pH 7.4) overnight at $4{ }^{\circ} \mathrm{C}$. On the next day, brains were stepwise dehydrated in a methanol/PBS concentration series before being stored at $-20^{\circ} \mathrm{C}$ in $100 \%$ methanol (Adolf et al., 2006; Schmidt et al., 2014).

\subsection{In situ hybridization}

In situ hybridization (ISH) was performed on vibratome brain slices (50 $\mu \mathrm{m}$ thickness) as previously described (Adolf et al., 2006; Schmidt et al., 2014). We used digoxigenin (DIG) labelled anti-sense probes for chromogenic in situ hybridization and DIG or dinitrophenol-11-UTP (DNP-11-UTP) labelled probes for fluorescent in situ hybridization. Probe synthesis and ISH on whole adult brains were performed as previously described (Adolf et al., 2006; Diotel et al., 2015; Lam et al., 2009; Rodriguez Viales et al., 2015). Briefly, after rehydration, brains were washed in $0.1 \%$ Tween, PBS buffer (PTw; $\mathrm{pH} 7.4$ ) and subsequently incubated in PTw containing proteinase $\mathrm{K}$ $(10 \mu \mathrm{g} / \mathrm{ml})$ at room temperature $\left(20^{\circ} \mathrm{C}\right)$ for $30 \mathrm{~min}$. Next, brains were post-fixed in 4\% PFA for $30 \mathrm{~min}$, washed in PTw and prehybridized for $3 \mathrm{~h}$ before overnight incubation at $65^{\circ} \mathrm{C}$ in hybridization buffer containing the DIG labelled probes. After several washing steps, brains were briefly incubated in blocking buffer, embedded in $2 \%$ agarose and sectioned using a Leica vibrating blade microtome VT1000 S at $50 \mu \mathrm{m}$ thickness. After a $1 \mathrm{~h}$ blocking step at room temperature, sections were incubated overnight at $4{ }^{\circ} \mathrm{C}$ with Anti-Digoxigenin-AP Fab fragments (1:4000, Roche, Cat\# 11093274910, RRID: AB_514497). Finally, sections were washed in PTw and stained with NBT/BCIP solution.

Fluorescent in situ hybridization was performed using tyramide amplification according to the manufacturer's instructions (TSA Plus Cyanine 3 System, Perkin Elmer, Boston, MA). Briefly, brains were treated with $3 \% \mathrm{H}_{2} \mathrm{O}_{2}$ in PBS before sectioning for inactivating endogenous peroxidase. After blocking for $1 \mathrm{~h}$, the sections were incubated with anti-dinitrophenol-HRP (1:200, Perkin Elmer) and/ or anti-digoxigenin-POD (poly) antibody (1:1000, Roche) and stained with tyramide $\mathrm{Cy} 3$ solution $(1: 100)$ in $0.002 \% \mathrm{H}_{2} \mathrm{O}_{2}$ in PBSTween $\mathbf{0 . 1 \%}$ as previously described (Yang et al., 2010).

Each ISH was repeated at least three times, and no specific staining was observed with sense probes (data not shown).

\subsection{Immunohistochemistry}

Immunohistochemistry was performed on free-floating $50 \mu \mathrm{m}$ thickness transverse vibratome sections as previously described by
Adolf and colleagues (Adolf et al., 2006), using the following primary antibodies: chicken anti-GFP (1:1000, Aves Labs, Cat\# GFP1020, RRID: AB_10000240), rabbit anti-GFP (1:1000, Torrey Pines Biolabs), mouse anti-PCNA (1:500, DAKO, Cat\# M0879, clone PC10; RRID: AB_2160651), rabbit anti-S100 (1:400, DAKO, Cat\# Z0311, RRID: AB_10013383) and mouse anti-HuC/D (1:300, Invitrogen, Cat\# A21271, Clone 16A11, RRID: AB_221448). The secondary Alexa fluor antibodies used for fluorescent staining were goat antichicken, anti-mouse and anti-rabbit from the Alexa series (Alexa 488, Alexa 546, Alexa 680; 1:1000, Invitrogen). The sections were mounted on slides with Aqua-Poly/Mount (Polysciences).

\subsection{Microscopy}

For bright field microscopy, pictures were acquired using a Leica compound microscope (DM5000B). For fluorescent microscopy, pictures were acquired using a laser scanning confocal microscope Leica TCS2 SP5 and processed using Leica software. Pictures were adjusted for brightness and contrast in Adobe Photoshop CS5.

\subsection{Nomenclature and abbreviations}

The nomenclature and the schemes of brain sections correspond to those provided in the zebrafish brain atlas (Wullimann et al., 1996).

A, anterior thalamic nucleus; APN, accessory pretectal nucleus; ATN, anterior tuberal nucleus; CCe, corpus cerebelli; Chab, habenular commissure; Chor, horizontal commissure; CM, corpus mamillare; CP, central posterior thalamic nucleus; CPN, central pretectal nucleus; Cpop, postoptic commissure; Cpost, posterior commissure; D, dorsal telencephalic area; Dc, central zone of dorsal telencephalic area; Dl, lateral zone of dorsal telencephalic area; Dm, medial zone of dorsal telencephalic area; DOT, dorsomedial optic tract; Dp, posterior zone of dorsal telencephalic area; DP, dorsal posterior thalamic nucleus; ECL, external cellular layer of olfactory bulb; EG, eminentia granularis; ENv, entopendoncular nucleus, ventral part; FR, fasciculus retroflexus; GL, glomerular layer of olfactory bulb; Had, dorsal habenular nucleus; Hav, ventral habenular nucleus; Hc, caudal zone of periventricular hypothalamus; Hd, dorsal zone of periventricular hypothalamus; Hv, ventral zone of periventricular hypothalamus; ICL, internal cellular layer of olfactory bulb; IL, inferior lobe; LH, lateral hypothalamic nucleus; LLF: lateral longitudinal fascicle; LR, lateral recess of diencephalic nucleus; MLF, medial longitudinal fascicle; NMLF, nucleus of medial longitudinal fascicle; PG, preglomerular nucleus; PGa, anterior preglomerular nucleus; PGl, lateral preglomerular nucleus; Pit, pituitary; PO, posterior pretectal nucleus; PP, periventricular pretectal nucleus; PPa, parvocellular preoptic nucleus, anterior part; PPp, parvocellular preoptic nucleus, posterior part; PR, posterior recess of diencephalic ventricle; PSp, parvocellular superficial pretectal nucleus; PTN, posterior tuberal nucleus; R, rostrolateral nucleus; RF, reticular formation; SC, suprachiasmatic nucleus; SD, saccus dorsalis; SO, secondary octaval population; TeO, tectum opticum; TL, torus longitudinalis; TLa, torus lateralis; TPp, periventricular nucleus of posterior tuberculum; TS, torus semicircularis; V, ventral telencephalic area; V3, third ventricle; VII, sensory root of the facial nerve; VIII, octaval nerve; VCe, valvula cerebelli; Vd, dorsal nucleus of ventral telencephalic area; VL, ventrolateral thalamic nucleus; VM, ventromedial thalamic nucleus; VOT, ventrolateral optic tract; Vp, postcommissural nucleus of ventral telencephalic area; $\mathrm{Vv}$, ventral nucleus of dorsal telencephalic area; ZL, zona limitans. 


\section{Conflict of interest}

The authors declare no conflict of interest.

\section{Role of authors}

ND, SR and US designed the experiments and supervised the work. ND and TB conducted the ISH experiments. ND and SR analyzed the ISH data and wrote the manuscript.

\section{Acknowledgements}

We thank Nadine Borel and the fish facility staff for fish care, Maryam Rastegar for her support with the microscopes, Rebecca Rodriguez Viales and Benjamin and Meltem Weger for discussion, and Thomas Dickmeis for advice, discussion and proof reading of the manuscript.

We are grateful for support by the EU IP ZF-Health (Grant number: FP7-242048), the Interreg Network for Synthetic Biology in the Upper Rhine valley (NSB-Upper Rhine), Helmholtz Initiative on Synthetic Biology (HISynBio) (Grant number: SO-078) and the BMBF funded network EraSysBio (Grant number: 03A095C).

\section{References}

Adolf, B., Chapouton, P., Lam, C.S., Topp, S., Tannhauser, B., Strähle, U., Götz, M., Bally-Cuif, L., 2006. Conserved and acquired features of adult neurogenesis in the zebrafish telencephalon. Dev. Biol. 295, 278-293.

Aloia, L., Gutierrez, A., Caballero, J.M., Di Croce, L., 2015. Direct interaction between Id 1 and Zrf1 controls neural differentiation of embryonic stem cells. EMBO Rep. $16,63-70$.

Armant, O., März, M., Schmidt, R., Ferg, M., Diotel, N., Ertzer, R., Bryne, J.C., Yang, L. Baader, I., Reischl, M., Legradi, J., Mikut, R., Stemple, D., van IJcken, W., van der Sloot, A., Lenhard, B., Strähle, U., Rastegar, S., 2013 Aug 15. Genome-wide, whole mount in situ analysis of transcriptional regulators in zebrafish embryos. Dev. Biol. 380 (2), 351-362. http://dx.doi.org/10.1016/j.ydbio.2013.05.006. Epub 2013 May 14.

Bai, G., Sheng, N., Xie, Z, Bian, W., Yokota, Y., Benezra, R., Kageyama, R., Guillemot, F. Jing, N., 2007. Id sustains Hes1 expression to inhibit precocious neurogenesis by releasing negative autoregulation of Hes1. Dev. Cell. 13, 283-297.

Baubet, V., Xiang, C., Molczan, A., Roccograndi, L, Melamed, S., Dahmane, N., 2012. Rp58 is essential for the growth and patterning of the cerebellum and for glutamatergic and GABAergic neuron development. Development 139, 1903-1909.

Braun, S.M., Jessberger, S., 2014. Adult neurogenesis: mechanisms and functional significance. Development 141, 1983-1986.

Chong, S.W., Nguyen, T.T., Chu, LT., Jiang, Y.J., Korzh, V., 2005. Zebrafish id2 developmental expression pattern contains evolutionary conserved and species-specific characteristics. Dev. Dyn. 234, 1055-1063.

Dickmeis, T., Rastegar, S., Lam, C.S., Aanstad, P., Clark, M., Fischer, N., Rosa, F., Korzh, V., Strahle, U., 2002. Expression of the helix-loop-helix gene id3 in the zebrafish embryo. Mech. Dev. 113, 99-102.

Diotel, N., Rodriguez Viales, R., Armant, O., Marz, M., Ferg, M., Rastegar, S. Strahle, U., 2015. Comprehensive expression map of transcription regulators in the adult zebrafish telencephalon reveals distinct neurogenic niches. J. Comp. Neurol. 523, 1202-1221.

Diotel, N., Vaillant, C., Gabbero, C., Mironov, S., Fostier, A., Gueguen, M.M., Anglade, I., Kah, O., Pellegrini, E., 2013. Effects of estradiol in adult neurogenesis and brain repair in zebrafish. Hormones Behav. 63, 193-207.

Edelmann, K., Glashauser, L., Sprungala, S., Hesl, B., Fritschle, M., Ninkovic, J., Godinho, L., Chapouton, P., 2013. Increased radial glia quiescence, decreased reactivation upon injury and unaltered neuroblast behavior underlie decreased neurogenesis in the aging zebrafish telencephalon. J. Comp. Neurol. 521, 3099-3115.

Grandel, H., Brand, M., 2013. Comparative aspects of adult neural stem cell activity in vertebrates. Dev. Genes. Evol. 223, 131-147.

Grandel, H., Kaslin, J., Ganz, J., Wenzel, I., Brand, M., 2006. Neural stem cells and neurogenesis in the adult zebrafish brain: origin, proliferation dynamics, migration and cell fate. Dev. Biol. 295, 263-277.

Havrda, M.C., Harris, B.T., Mantani, A., Ward, N.M., Paolella, B.R., Cuzon, V.C., Yeh, H.H., Israel, M.A., 2008. Id2 is required for specification of dopaminergic neurons during adult olfactory neurogenesis. J. Neurosci. Off. J. Soc. Neurosci. $28,14074-14086$.

Heng, J.I., Qu, Z., Ohtaka-Maruyama, C, Okado, H., Kasai, M., Castro, D., Guillemot, F. Tan, S.S., 2015. The zinc Finger transcription factor RP58 negatively regulates Rnd2 for the control of neuronal migration during cerebral cortical development. Cereb. Cortex 25, 806-816.
Hirai, S., Miwa, A., Ohtaka-Maruyama, C., Kasai, M., Okabe, S., Hata, Y., Okado, H., 2012. RP58 controls neuron and astrocyte differentiation by downregulating the expression of Id1-4 genes in the developing cortex. EMBO J. 31, 1190-1202.

Jen, Y., Manova, K., Benezra, R., 1997. Each member of the Id gene family exhibits a unique expression pattern in mouse gastrulation and neurogenesis. Dev. Dyn. 208, 92-106.

Jung, S., Park, R.H., Kim, S., Jeon, Y.J., Ham, D.S., Jung, M.Y., Kim, S.S., Lee, Y.D. Park, C.H., Suh-Kim, H., 2010. Id proteins facilitate self-renewal and proliferation of neural stem cells. Stem Cells Dev, 19, 831-841.

Kitajima, K., Takahashi, R., Yokota, Y., 2006. Localization of Id2 mRNA in the adult mouse brain. Brain Res. 1073-1074, 93-102.

Lam, C.S., März, M., Strähle, U., 2009. gfap and nestin reporter lines reveal characteristics of neural progenitors in the adult zebrafish brain. Dev. Dyn. 238, 475-486.

Langlands, K., Yin, X., Anand, G., Prochownik, E.V., 1997. Differential interactions of Id proteins with basic-helix-loop-helix transcription factors. J. Biol. Chem. 272, 19785-19793.

Lasorella, A., Benezra, R., Iavarone, A., 2014. The ID proteins: master regulators of cancer stem cells and tumour aggressiveness. Nat. Rev. Cancer 14, 77-91.

Lau, C., Ng, L., Thompson, C., Pathak, S., Kuan, L, Jones, A., Hawrylycz, M., 2008. Exploration and visualization of gene expression with neuroanatomy in the adult mouse brain. BMC Bioinforma. 9, 153.

Lee, J.C., Chen, B.H., Cho, J.H., Kim, I.H., Ahn, J.H., Park, J.H., Tae, H.J. Cho, G.S. Yan, B.C., Kim, D.W., Hwang, I.K., Park, J., Lee, Y.L, Choi, S.Y., Won, M.H., 2015 Changes in the expression of DNA-binding/differentiation protein inhibitors in neurons and glial cells of the gerbil hippocampus following transient global cerebral ischemia. Mol. Med. Rep. 11, 2477-2485.

Lindsey, B.W., Darabie, A., Tropepe, V., 2012. The cellular composition of neurogenic periventricular zones in the adult zebrafish forebrain. J. Comp. Neurol. 520 2275-2316.

Lindsey, B.W., Tropepe, V., 2006. A comparative framework for understanding the biological principles of adult neurogenesis. Prog. Neurobiol. 80, 281-307.

Ling, F., Kang, B., Sun, X.H., 2014. Id proteins: small molecules, mighty regulators. Curr. Top. Dev. Biol. 110, 189-216.

Liu, H., Jia, D., Li, A., Chau, J., He, D., Ruan, X., Liu, F., Li, J., He, L, Li, B., 2013. p53 regulates neural stem cell proliferation and differentiation via BMP-Smad1 signaling and Id1. Stem Cells Dev. 22, 913-927.

Lyden, D., Young, A.Z., Zagzag, D., Yan, W., Gerald, W., O'Reilly, R., Bader, B.L., Hynes, R.O., Zhuang, Y., Manova, K., Benezra, R., 1999. Id1 and Id 3 are required for neurogenesis, angiogenesis and vascularization of tumour xenografts. Nature 401, 670-677.

März, M., Chapouton, P., Diotel, N., Vaillant, C., Hesl, B., Takamiya, M., Lam, C.S. Kah, O., Bally-Cuif, L., Strähle, U., 2010. Heterogeneity in progenitor cell subtypes in the ventricular zone of the zebrafish adult telencephalon. Glia 58, $870-888$.

März, M., Schmidt, R., Rastegar, S., Strähle, U., 2011. Regenerative response following stab injury in the adult zebrafish telencephalon. Dev. Dyn. 240, 2221-2231.

Nam, H.S., Benezra, R., 2009. High levels of Id1 expression define B1 type adult neural stem cells. Cell. Stem Cell. 5, 515-526.

Neuman, T., Keen, A., Zuber, M.X., Kristjansson, G.I., Gruss, P., Nornes, H.O., 1993. Neuronal expression of regulatory helix-loop-helix factor Id2 gene in mouse. Dev. Biol. 160, 186-195.

Ng, L., Bernard, A., Lau, C., Overly, C.C., Dong, H.W., Kuan, C., Pathak, S., Sunkin, S.M. Dang, C., Bohland, J.W., Bokil, H., Mitra, P.P., Puelles, L., Hohmann, J. Anderson, DJ, Lein, E.S. Jones, A.R. Hawrylycz, M., 2009. An anatomic gene expression atlas of the adult mouse brain. Nat. Neurosci. 12, 356-362.

Norton, J.D., 2000. ID helix-loop-helix proteins in cell growth, differentiation and tumorigenesis. J. cell Sci. 113 (Pt 22), 3897-3905.

Ohtaka-Maruyama, C., Miwa, A., Kawano, H., Kasai, M., Okado, H., 2007. Spatial and temporal expression of RP58, a novel zinc finger transcriptional repressor, in mouse brain. J. Comp. Neurol. 502, 1098-1108.

Paolella, B.R., Havrda, M.C., Mantani, A., Wray, C.M., Zhang, Z., Israel, M.A., 2011. p53 directly represses Id2 to inhibit the proliferation of neural progenitor cells. Stem Cells 29, 1090-1101.

Patel, D., Morton, D.J., Carey, J., Havrda, M.C. Chaudhary, J., 2015. Inhibitor of differentiation 4 (ID4): from development to cancer. Biochim. Biophys. Acta 1855, 92-103.

Pellegrini, E., Mouriec, K., Anglade, I., Menuet, A., Le Page, Y., Gueguen, M.M. Marmignon, M.H., Brion, F. Pakdel, F, Kah, O, 2007. Identification of aromatasepositive radial glial cells as progenitor cells in the ventricular layer of the forebrain in zebrafish. J. Comp. Neurol. 501, 150-167.

Perk, J., Iavarone, A., Benezra, R., 2005. Id family of helix-loop-helix proteins in cancer. Nat. Rev. Cancer 5, 603-614.

Riechmann, V., Sablitzky, F., 1995. Mutually exclusive expression of two dominantnegative helix-loop-helix ( $\mathrm{dnH} H \mathrm{H})$ genes, Id 4 and Id3, in the developing brain of the mouse suggests distinct regulatory roles of these dnHLH proteins during cellular proliferation and differentiation of the nervous system. Cell. Growth Differ. 6, 837-843.

Rodriguez Viales, R., Diotel, N., Ferg, M., Armant, O., Eich, J., Alunni, A., März, M. Bally-Cuif, L., Rastegar, S., Strähle, U., 2015. The helix-loop-helix protein id 1 controls stem cell proliferation during regenerative neurogenesis in the adult zebrafish telencephalon. Stem Cells 33, 892-903.

Sawai, S., Campos-Ortega, J.A., 1997. A zebrafish Id homologue and its pattern of expression during embryogenesis. Mech. Dev. 65, 175-185. 
Schmidt, R., Beil, T., Strähle, U., Rastegar, S., 2014. Stab wound injury of the zebrafish adult telencephalon: a method to investigate vertebrate brain neurogenesis and regeneration. J. Vis. Exp. JoVE e51753.

Schmidt, R., Strähle, U., Scholpp, S., 2013. Neurogenesis in zebrafish - from embryo to adult. Neural Dev. 8,3 .

Sikder, H.A., Devlin, M.K., Dunlap, S., Ryu, B., Alani, R.M., 2003. Id proteins in cell growth and tumorigenesis. Cancer Cell. 3, 525-530.

Sugimori, M., Nagao, M., Bertrand, N., Parras, C.M., Guillemot, F., Nakafuku, M., 2007. Combinatorial actions of patterning and HLH transcription factors in the spatiotemporal control of neurogenesis and gliogenesis in the developing spinal cord. Development 134, 1617-1629.

Sun, X.H., Copeland, N.G., Jenkins, N.A., Baltimore, D., 1991. Id proteins Id 1 and Id2 selectively inhibit DNA binding by one class of helix-loop-helix proteins. Mol. Cell. Biol. 11, 5603-5611.

Thisse, B., Pflumio, S., Fürthauer, M., Loppin, B., Heyer, V., Degrave, A., Woehl, R. Lux, A., Steffan, T., Charbonnier, X.Q., Thisse, C., E.o.t.z.g.d.e.N.R.R.Z.D.D.S., 2001 Expression of the zebrafish genome during embryogenesis (NIH R01 RR15402) ZFIN Direct Data Submiss. http://zfin.org http://zfin.org.

Tzeng, S.F., 2003. Inhibitors of DNA binding in neural cell proliferation and differentiation. Neurochem. Res. 28, 45-52.

Tzeng, S.F., de Vellis, J., 1998. Id1, Id2, and Id3 gene expression in neural cells during development. Glia 24, 372-381.
Uribe, R.A., Gross, J.M., 2010. Id2a influences neuron and glia formation in the zebrafish retina by modulating retinoblast cell cycle kinetics. Development 137 , 3763-3774.

Uribe, R.A., Kwon, T., Marcotte, E.M., Gross, J.M, 2012. Id2a functions to limit Notch pathway activity and thereby influence the transition from proliferation to differentiation of retinoblasts during zebrafish retinogenesis. Dev. Biol. 371, 280-292.

Westerfield, M., 2007. The Zebrafish Book. University of Oregon Press, Eugene, OR. Wullimann, M., Rupp, B., Reichert, H., 1996. Neuroanatomy of the Zebrafish Brain: A Topological Atlas. Birhaüser Verlag, Basel, Switzerland, pp. 1-144.

Xiang, C., Baubet, V., Pal, S., Holderbaum, L, Tatard, V., Jiang, P., Davuluri, R.V., Dahmane, N., 2012. RP58/ZNF238 directly modulates proneurogenic gene levels and is required for neuronal differentiation and brain expansion. Cell Death Differ. 19, 692-702.

Yang, L., Ho, N.Y., Müller, F., Strähle, U., 2010. Methyl mercury suppresses the formation of the tail primordium in developing zebrafish embryos. Toxicol. Sci. $115,379-390$.

Yokota, Y., 2001. Id and development. Oncogene 20, 8290-8298.

Zupanc, G.K., 2008. Adult neurogenesis and neuronal regeneration in the brain of teleost fish. J. Physiol. Paris 102, 357-373.

Zupanc, G.K., Hinsch, K., Gage, F.H., 2005. Proliferation, migration, neuronal differentiation, and long-term survival of new cells in the adult zebrafish brain. J. Comp. Neurol. 488, 290-319. 